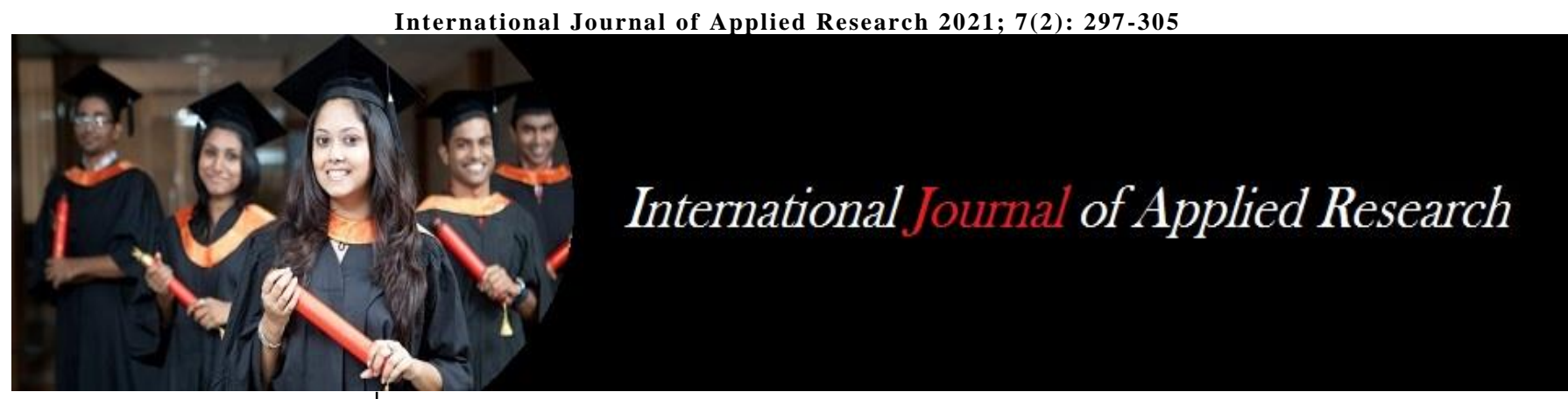

ISSN Print: 2394-7500

ISSN Online: 2394-5869

Impact Factor: 8.4

IJAR 2021; 7(2): 297-305

www.allresearchjournal.com

Received: 16-12-2020

Accepted: 18-01-2021

Sheetal Yadav

Ph.D. Research Scholar,

School of Education, Jaipur

National University,

Rajasthan, India

Grishma Shukla

Associate Professor, School of

Education, Jaipur National

University, Rajasthan, India

Corresponding Author:

Sheetal Yadav

Ph.D. Research Scholar,

School of Education, Jaipur

National University,

Rajasthan, India

\section{Learning styles: A detailed literature review}

\author{
Sheetal Yadav and Grishma Shukla
}

DOI: $\underline{\text { https://doi.org/10.22271/allresearch.2021.v7.i2e.8291 }}$

\section{Abstract}

Fundamental elements of learning can be an inevitable witness. A lot of pedagogic studies have been carried out to explore and analyse various learning styles. Many authors have projected that the flexibility to typify student learning styles will augment the academic experiences. The current study offers attention to the different aspects of learning and discusses the constraints and possibilities of learning styles in academic studies.

Keywords: learning, pedagogy, analysis, academic, study, self-regulated

\section{Introduction}

In the present study, the researcher consulted the related literature available like; Journals on Educational Research, Encyclopedia of Educational Research, etc. for having an acknowledgment regarding the potentiality of the problem from all these and other sources. The researcher was able to know that the problem at hand was interesting, significant, and feasible. Literature provides the procedures followed, devices used for data collection, and conclusions arrived at similar types of studies. The literature review is limited to studies focusing on learning styles adopted in educational institutions. Here are some of the studies related to learning styles:

\section{Interactive and Social Learning}

Cheng \& Tsai (2019) ${ }^{[9]}$ investigated a case study of the students' learning experiences and teacher-student interaction patterns throughout virtual field visits in an elementary room. The study finds that tutorial proof for examining the academic influences of immersive video games with head-mounted displays has been comparatively restricted heretofore, above all for virtual field visits which permit academics to guide students to explore learning parts in virtual environments. The study invited school students to interact in an immersive virtual outing that was a part of 2 weeks' land site on the educational subject of social studies. The educational experiences of the scholars, i.e., perceived presence, psychological feature beliefs modification, and attitudes were investigated and therefore the teacher-student interaction behaviors within the learning activity were explored. The results of the study showed that the motivation of the scholars was usually increased, notably for the diminishment of check anxiety. Kucuk \& Sisman (2017) ${ }^{[19]}$ investigated the activity patterns of elementary students and academics in matched artificial intelligence instruction. It showed some variations in problem level of activities between the boys and ladies. The authors notice that mistreatment of artificial intelligence in education could be a valuable tool for developing learners' psychological features moreover as social skills. it's greatly attracted the interest of educators and researchers from school to pedagogy. The study sheds light on the activity patterns of elementary students and academics in a matched artificial intelligence instruction method. It finds that steerage of the academics considerably followed the expressing behavior of the scholars and sharing their concepts that followed the teachers' queries. Results of this study are often taken into thought within the style of the educational surroundings. Vale et al. (2017) ${ }^{[43]}$ investigated the capability of human and non-human culture by examining what we tend to mean by the term culture and whether or not, and to what extent, a variety of core cultural components- innovation, social learning processes, and transmission biases are 1 shared across the primate order. 
The study talked regarding the additive culture, the power to come up with advanced cultural traits by building upon existing behavior patterns; and explores whether or not nonhuman primates, like humans, exhibit such cultural progress. Macpherson, Haggons \& Reicks (2000) ${ }^{[22]}$ investigated the interactive preparation lessons for elementary students and fogeys. The target of this study was to develop interactive preparation lessons for grade I-IV learners and their oldsters or caregivers and pilot check within the home setting employing a cooperative model with cooperative education educators serving as community partners with room academics. Jih \& Reeves (1992) ${ }^{[14]}$ investigated interactive learning systems The difficulty of understanding the structure and functions of computer programs is particularly acute once learners are given the liberty to explore machinereadable text materials within which the chance of disorientation is robust. Mental model theory is an effort to model and make a case for human understanding of objects and phenomena throughout learning and other activities. Analysis of mental models in human-computer interaction will determine vital characteristics of psychological feature processes and facilities within the development of researchbased tips for coming up with interactive learning systems. This text demands programmatic analysis on learners' mental models and provides tips for the conduct of such analysis.

\section{Innovative and Experiential Learning}

Tan \& Vicente (2019) ${ }^{[40]}$ investigated an innovative experiential learning approach. This paper projected a cooperative approach with the merchandise style course to conduct promoting management within the undergrad program to realize the abilities essential to the 21 st-century. The study aims to give a case of innovative experiential learning in teaching a sophisticated millimetre course by transferral in students from alternative programs; i.e.cooperative learning and experiential learning. Rather than the standard teacher-centric pedagogy and therefore the use of case studies, this projected approach is student-centered learning. Students found the new technique to be effective in terms of applying theory in a real state of affairs, rising their ability to spot wants and opportunities, developing actual services that supported the known wants, operating with a knowledge base team, enhancing their social skills, developing their leadership skills, rising their communication skills, and inspired them to stay learning. The study additionally discusses the areas for enhancements. Curdy (2013) [26] investigated the low-priced project innovation within the physics and house administration. This study provides a history of The National Aeronautics and Space Administration (NASA)'s expertise with lowpriced innovation. The author instructed that each initial team-based approach and therefore the systems management approach have benefit ciao as managers pay shut attention to the necessities every approach imposes. Analysis of the study instructed that the trouble comes from a misapplication of management techniques developed for the team-based approach.

\section{Game-Based Learning}

Park et al. (2019) [31] investigated performance vs. completion contingent reward for game-based learning. They examined the effectiveness of different reward structures in group action learning and game for game-based learning. In step with them, performance-contingent rewards turnout higher levels of learning and motivation relative to completion-contingent rewards. Their projected integration strategy is long for several alternative learning domains. The study extended previous work on external integration style by examining the effectiveness of different reward structures in group action learning and game. It proposes a performance-contingent reward as a replacement integration mechanism and its effects on learning, motivation, engagement, and system perception square measure assessed, vis-a-vis a completion-contingent reward. The results from the experiment show that the projected reward structure produces a statistically important increase within the level of learning, motivation, and engagement. The results obtained within the study were extremely encouraging for game-based learning and its relevance. Mackenzie, Son \& Eitel (2018) [21] investigated the employment of doors journey to reinforce intrinsic motivation and engagement in science and physical activity. The study found an associating degree integrated approach to addressing each problem by exploring student experiences during a pivot outside journey primarily based on science $d$ and their teachers' school settings before and after this course. They explored outside physical activity and science learning during a publically operated residential science faculty program primarily based. The findings give preliminary support for more developing and evaluating journey education and recreation programs with the twin aims of up student engagement in science education and physical activity. The authors' counsel that integrated outside journey primarily based programs could give intrinsic motivation to participants to have interaction in each physical activity furthermore as science education. Such programs give a unique means of addressing pressing social problems i.e. inactive lifestyles, underperformance in science. Raptis, Fidas \& Avouris (2018) ${ }^{[33]}$ investigated the effects of mixed-reality on players' behavior and immersion during a cultural business game. This study centered on the immersion among knowledge, technology, and cultural heritage play. In step with them, mixed-reality environments introduce innovative human-computer interaction paradigms power-assisted by increased visual content presentation, that need end-users to perform excessive psychological feature tasks associated with visual attention, search, processing, and comprehension. They found that mixed-reality interaction realms amplified the results of human psychological feature experience towards game-specific interaction behavior and visual behavior. Madani, Pierce \& Mirchi (2017) ${ }^{[23]}$ reviewed serious games for environmental management. They talked regarding the requirement for the same methodology to look at the effectiveness of significant games. The study provides a summary of game primarily based learning and therefore the state of significant games for environmental management, and offers insight into their potential as effective tools in facilitating environmental education. The authors suggest that the study should continue on serious games potency. Khenissi et al. (2016) [15] investigated the link between learning designs and genres of games. This study investigated the link between one in all the learner characteristics, specifically learning designs and genres of games. The study centered on four relationships between two dimensions of the FelderSilverman learning experience and four genres of laptop games. Results of the study experimentation valid two 
relationships among four and rejected two. Confirmed relationships will be exploited by lecturers and E-Learning recommendation systems to produce a lot of customized recommendations to learners.

\section{Self-Regulated Learning}

Al-Abdullatif \& Wang (2020) ${ }^{[1]}$ aimed to research the impact of a flipped room on the self-regulated learning (SRL) and tutorial action of seventh-grade school students. A quantitative approach was wont to compare the standard and flipped room approaches. The information was obtained by victimising the motivating ways for Learning. The results indicated that sixty-four seventh-grade participants incontestably had a good-to-high level of active SRL at intervals in the flipped room setting. Moreover, the coed participants perceived to self-regulate their metacognitive learning ways within the flipped room setting over those within the ancient learning setting. In terms of their tutorial action, no statistically important distinction was detected between the standard and flipped lecture rooms. Associations between the scholars SRL and tutorial action were known, and several other implications and proposals were derived. Cazan (2020) ${ }^{[8]}$ investigated the development of self-regulated learning skills. The study relies on the social-cognitive perspective of self-regulated learning and focuses on its development in educational settings. This study examined the impact of associate degree intervention on the event of self-regulated learning ways at a coursespecific level. The interchangeability of the trained ways in a completely different learning context and also the risk that the coaching causes the advance of learning motivation and activity ways, though they weren't expressly trained were conjointly examined. Additionally, the results of a prolongment of the intervention within the second semester were investigated. The advance of the training skills was conjointly assessed through the content analysis of the training journals competed by the scholars throughout the intervention program. The author tends to use a mixed technique style to look at the changes in students' selfregulated learning created before and once the intervention. The participants were 1st-year science and Education Sciences, students. Throughout an educational year, the scholars were trained to use techniques combining psychological features and metacognitive skills. All the ways were enforced through implicit coaching, being enclosed as course tasks, and practiced in an exceedingly domain-specific context. The study discovered that the intervention had positive effects on self-regulated learning skills, the scholars within the intervention cluster differed considerably at the tip of the intervention from the scholars within the management cluster. Another finding was the interchangeability of the trained ways to completely different learning contexts. Albeit self-regulated learning skills practiced implicitly in an exceeding context, their observation may lead to generalization and increase the transfer opportunities. Zoltowski \& Teixeira (2020) ${ }^{[46]}$ investigated the development of self-regulated learning. Self-regulated learners manage their tutorial demands in a very versatile and demanding approach to attain their goals. This study aimed to grasp the event of self-regulated learning in school students. Anticipation, performance, and self-reflection phases. Specific development trajectories were discovered and self-efficacy was a rational motive to propose objectives and techniques. Self-regulated learning appears to at the start depend upon external regulators for its consolidation. It was noted the importance of promoting tutorial feedback connected not solely to the results of the evaluations, however conjointly to the method of studies, so contributing to putting together a lot of autonomous, crucial, and self-regulated learners. Mirhosseini, Lavasani \& Hejazi (2018) ${ }^{[27]}$. Investigated the Effectiveness of Self-Regulation Learning Skills on Motivational and Academic Variables among Students. The purpose of this study was to verify the effectiveness of self-activating learning ways on motivation, self-efficacy, and educational performance of fifth grade feminine students in science lessons. For this purpose, two categories were selected as cluster sampling. One among the categories was elite because the experimental group, they were provided with a self-regulation educational program in twelve sessions of one hour, and the management cluster failed to receive the program. The analysis technique was experimental and its style was quasi-experimental, pre-test, and post-test. To live the variables, Harter's academic Motivation Questionnaire and the educational form were used. Students' results of sciences examination and the researcher's self-structured four-choice take a look at were used to assess the educational achievement. The questionnaires were provided to the scholars before and once the coaching. One-factor variance analysis was accustomed to analysing the information. The results of the study showed that self-regulating learning ways have a significant impact on students' motivation and education. The educational performance of scholars within the sciences accrued. Yot-Domínguez \& Marcelo (2017) ${ }^{[45]}$ investigated self-regulated learning using digital technologies. Analysed the method by that students- whether at university or not; manage and facilitate their learning has been a continual academic analysis drawback. Recently, the question arises concerning however the event of ways happening throughout the same method may be created easier by victimisation technologies. In an attempt to understand whether or not university students extremely use digital technologies to set up, organize and facilitate their learning, we've got projected 3 analysis queries. That technologies do university students use to self-regulate their learning? What self-regulated learning ways do they develop victimisation technologies? What profiles may be known among students that support their use of self-regulation ways with technology? To answer these queries, the "Survey of SelfRegulated Learning with Technology at the University" was designed. Data from a sample cluster with 711 students from numerous universities set within the geographic region (Spain) was collected with this survey. The results indicate that university students, even once they are frequent users of digital technology, they have a tendency to not use these technologies to manage their learning method. Of all technologies analysed, net data search and instant communication tools are used regularly. In turn, the foremost generalised self-regulation learning ways are those relative to social support. However, students take issue with one another concerning their use and frequency. There are teams of scholars World Health Organization builds use of self-regulation ways once learning with technologies. In this regard, 2 distinctive teams of scholars are known, World Health Organization show differentiated self-regulated levels. Roick \& Ringeisen (2016) investigated students' math performance in pedagogy. The study examined the role of self-regulated learning and self-efficacy. 
Investigation on the role of learning ways and self-efficacy for arithmetic performance in pedagogy is distributed, particularly if psychological features and metacognitive ways square measure thought of. Future longitudinal analysis is bonded to demonstrate the causative role of selfefficacy as an intercessor between learning strategy use on math performance. It finds that in terms of implications, interventions could facilitate to foster the students' awareness for associate degree integrated use of psychological features and metacognitive ways. Robledo \& Ayala (2016) [36] investigated a holistic self-regulated learning model. This analysis projected a wise sequencing approach that permits Technology increased Learning systems to guide students to manage their learning method. The essence of the proposal may be a holistic self-regulated learning (SRL) model that inspired the scholars to develop higher-order thinking through the application of metacognitive skills, psychological feature factors, and activity affairs to become attentive to their learning endeavors. The study applied this approach as a part of the sequencing module of the Learning system, wherever students follow its urged psychological feature ways to help them throughout the programming of management instrumentation. The study finds that though experimental subjects had to cope with higher psychological feature load, they're expected to achieve higher learning achievements than their management peers. Moos \& Ringdal (2012) ${ }^{[28]}$ investigated self-regulated learning in the Classroom. Empirical research has supported the long control assumption that individual variations exist in however students learn. Recent method advancements have allowed academic analysis to look at not solely what students learn, however conjointly however they learn. analysis has found that active involvement in learning, as well as setting meaningful goals, choosing acceptable and task-specific ways, observation psychological feature levels, and adapting supported feedback are all completely associated with learning outcomes. However, will lecturers support students' development and use of those learning processes? The goal of this paper is to look at an analysis that has used the Self-Regulated Learning (SRL) theory to contemplate this broad question. Method advancements recently employed in this field of analysis, numerous SRL theoretical frameworks guiding this analysis, and studies that by trial and error examined self-regulation with each preservice and in-service educator are mentioned. The paper concludes with the theoretical, method, and sensible implications of the reviewed studies. Ozan, Gundogdu, Bay \& Celkan (2012) ${ }^{[30]}$. Investigated a study on the University Students' Self-Regulated Learning Strategies Skills and Self-Efficacy Perceptions in Terms of Different Variables. The purpose of this study is to research the university students' selfregulated learning strategy skills and self-efficacy perceptions in terms of various variables at intervals in the frame of the "Curriculum Development and Instruction" course. Survey methodology was benefited during this descriptive study. The study cluster consisted of 310 uni versity students registered to totally different 3 schools in $\mathrm{U}$ niversity, Turkey, and taking the "Curriculum Development and Instruction" course to be related to teaching affairs withi $\mathrm{n}$ the future. At the top of the analyses, the university studen ts' self-efficacy perceptions and self-

regulated learning strategy skills were found high and theref ore the values obtained through the applied math analyses $\mathrm{w}$ ere statistically totally different consistent with gender and s chool variables. Pintrich (1995) ${ }^{[32]}$ investigated the understanding of self-regulated learning. Selfregulated learning is a crucial element of learning for faculty students. Students will learn the way to become self-regulated learners, and schools will foster self-regulated learning in their school rooms.

\section{Integrated Learning}

Fleming \& Pretti (2019) ${ }^{[11]}$ investigated the impact of workintegrated learning (WIL) students on geographical point dynamics. The aim was to see whether or not a WIL student caused changes to geographical point team dynamics. The authors used the mixed ways approach information was collected from WIL students and supervisors. Pre-placement preparation is required thus students are attentive to positive behaviours and also the potential power relationships or tensions they will be exposed to. Mawdsley \& Willis (2019) [25] explored an associate degree integrated program in pharmacy. The study talked regarding students' views on the intimate with program and pedagogies supporting integrative learning. The study checked out what education methods do students acknowledge as samples of integration and the way will integrate the program from learning. Findings of the study recommend that integrative learning is intimate with, once teaching is advisedly designed to be horizontally integrated between disciplines, once the integration is created specific, and once the content is applied to pharmacy follow. It conjointly finds that integrated assessments were thought of to be cognitively troublesome. Aljohani et al. (2018) ${ }^{[2]}$ investigated one amongst associate degree integrated framework for course custom-made student learning analytics dashboard. This study aimed to speak to a framework for Learning Analytics to support the integrated management of end-to-end learning information. Authors given the analysis foundations of an enquiry image for the combination of a Learning Analytics Dashboard. Finally, they gave the most findings of associate degree empirical study that proves the capability of learning analytics to boost the learners' system worth adding learning services. The projected framework exploited psychological feature computing for the sweetening of deciding in education by proving the capability of Learning Analytics to reveal hidden patterns of learners' behaviour. They found differing types of tools helped them to form a record of expertise whereas increasing completely different aspects of expedition learning by planning the educational atmosphere, building activities, planning lessons, and organising the atmosphere for learning. With the assistance of technology, students will produce maps and documents associated with social problems and historical places they encounter throughout their cultural exchange with the assistance of digital video, photography, and web site style. Labib, Canos \& Penades (2017) [20] investigated ways in which to integrate learning experience models integration. during this study, authors introduced a learner's characteristics metaphysics supported making interconnections between the various learning experience model dimensions and learning designs with the relevant learner's characteristics, that- It helps instructors to boost and individualize the educational content; It will advocate learning materials to learners consistent with their learning characteristics and preferences; It will offer each instructor and learners with in-depth data regarding however they will improve their 
teaching and learning abilities, and It can improve communications and interaction between humans and computers by specifying the linguistics of the educational experience models' characteristics. Wong \& Nguyen (2016) [44] investigated the introduction of associate degree integrated programmes in pharmacy. The needs of the study were to assess the first impact of a brand new integrated pharmacy program not off course evaluations and learning of the clinical sciences in comparison to the normal curriculum and to explain provision enhancers and challenges that ought to be thought of before and through the rollout of comparable curricula. The findings of the study showed that once comparing student course evaluations, there have been no vital variations. The study conjointly provided insight on a shift amount between ancient and integrated info approaches during an authorized Pharm D program.

\section{Expedition Learning}

Reid \& Kampman (2020) ${ }^{[34]}$ explored the psychology of extended period expeditionary adventures. This study aimed to explore the lived experiences of extended-period expedition journeys to know why these people adventure, and what they understand gaining from such experiences. Most add this space to this point has centered on exploring pre-determined components of adventuring like risk, stressors, and temperament traits. However, the aim has been to know why of this specific participant pool; the means and perceived advantages of happening a permanent journey or expedition. The results suggested that enduring expeditionary adventures have the potential to accelerate and amplify individuals' growth and facilitate psychological well-being. Asfeldt, Hvenegaard, \& Stern. (2018) [3] investigated the group writing, reflection, and discovery as a model for enhancing learning on wilderness educational expeditions. This study aimed to research students' perceptions of a group journal activity (GJA) on learning to sweeten and to give a model that illustrates the reflectivelearning method of the GJA. A positive relationship exists between students' taking part in the GJA and self-reported perception of learning. Students report the GJA as having similar edges as ancient personal journal-writing with the additional edges of promoting learning from others' views, enhancing understanding of others, promoting reflective communication skills, and providing a tangible record of expertise that permits continued reflection and learning. A method model illustrates the algorithmic cycle o f writing. Kimmes (2017) ${ }^{[16]}$ investigated the benefits of Experiential Learning in an Outdoor Expedition Setting. Ex periential learning has been around for hundreds of years. This is one of many pedagogical methods that teachers use today. Technological advancements in the classroom, and modern-day society, is creating withdrawal from these experiential hands-on learning tactics in an outdoor setting. To understand the extreme importance and benefits of school-level students to have the interest and incorporate an experiential learning experience in their lives, presented below in the literature review there is content backing this Approach. Through the literature review findings, my personal experience on expeditions, and in the field teachings, the Rediscovering North America experiential learning curriculum has been created. The resulting curriculum consists of lessons for any school level student to pursue an expedition like the Rediscovering North
America canoe trip. Experiential learning lessons about the structure and function of the brain, how students make decisions, interact amongst each other through group dynamics and expedition behavior. Becoming stewards of the land through environmental topics like leave no trace, watershed, and human impact. Lastly, observing the natural world through the phenology lenses, understanding biomes, species development, and migration. All of which would be experienced during an expedition-style trip. Together, the contents of my research and project included with my paper answer, what are the benefits of school level students participating in an experiential learning expedition? Stern (2016) ${ }^{[39]}$ investigated leadership and policy in EL middle school. The author explored educators' sense of creating responses to No Student Left Behind and also the Common Core State Standards at one urban expeditionary learning school. Sense-making theory and inquiry as a stance used as complementary abstract frameworks to remove and analyze teachers' and administrators' conceptions, critiques, and responses to those federal initiatives. Analysis disclosed that scrupulous neglect and scrupulous compliance were the first responses to those initiatives, which enabled educators at the varsity to keep up an active, authentic student-centered course of study and instruction aligned with the EL philosophy. Camillo (2015) [7] investigated a knowledge domain expedition supporting the Expeditionary Learning Outward certain model. The author investigated it in an exceedingly international history category in an urban charter high school to know what happens throughout an expedition. The author indicated learners were engaged in learning regarding problems with security and privacy, however didn't create knowledge domain connections between international history and their different categories. The study targeted the advantages and challenges of implementing a knowledge domain approach to teaching furthermore because they want added support for academics and wish to implement knowledge domain curricula. Schaffhauser (2015) [38] investigated the employment of expedition learning's open supply information. The author found that Denver Public faculties are doubling down on their relationship with learning expeditions. Expedition Learning may be a non-profit academic organization that has worked closely with the Denver district to remake one among its faculties. A number of the changes there enclosed extended learning time plans, that another three hundred hours of student time throughout the school year. This semiconductor diode to forty-five minutes of additional education daily and enriched Wednesdays. Here the scholars took active half in dance, art, cooking, technology and science, and different topics. The organization is additionally designing for skilled development to 600 academics and directors around the district this summer. The modules build data and skills toward performance tasks, supply differentiated supports for learners, and supply freelance reading and selection opportunities. Jahnke, Norqvist \& Olsson (2014) [13] investigated the digital didactical designs of learning expeditions. Current studies on media tablets illustrated that mobile technology might improve learning once actually integrated into learning settings. In a very study of Scandinavian school rooms, the question was however academics adopt and integrate media tablets in their teaching practices to supply learning opportunities for his or her students. Seven K-9 faculties enforced media tablets for around a pair of students aged 6- 
16 and ca. a hundred and seventy academics in a very $1: 1$ programme launched in 2012. Mixed ways, interviews, classroom observations, and on-line surveys are applied. The findings illustrate new kinds of teaching practices. finding out technology integration from the angle of a sociotechnical-pedagogical observer reveals the interrelatedness of teaching processes and quality of learning. This study shows five kinds of digital informative style in observation, that have an effect on tablet-mediated learning expeditionsmost of the styles boost learning, others prohibit learning. Barrer \& Haimson (2013) ${ }^{[5]}$ investigated the impacts of EL middle schools on academic achievement. The study found that EL students perform higher in reading and mathematics than their counterparts in alternative public faculties. Ikpeze (2013) ${ }^{[12]}$ investigated the increasing engagement of the urban students towards the EL. This paper documented the findings of a case study of K-10 urban EL school. Drawing on theoretical views according to the mental object theory, information was collected from a range of sources that enclosed a survey, interviews, field notes from room observations, and different faculty activities. Thematic analysis was wont to analyze information. The study disclosed that EL in school was self-made thanks to the school culture, structure, teachers' commitment, and community engagement. This suggests that urban faculty reform hinges on selecting the proper reform model for committed lecturers and an enticing syllabus. Owens (2013) [29] investigated that expedition learning unshackling property education. The author found that youth mandated to travel to figure daily and problems like indoor areas, hard, plastic seats, and spurious menial tasks characterize their geographic point. This is often an era wherever the life support systems of our planet square measure in peril and enormous populations sleep in economic conditions and violence. There's an illogical disconnection between however the education goes on and the way it's required to facilitate a deep cultural-revolution. Academic square measure instructed to show within the same method, for instance- sitting in rows within establishments of upper learning, taking notes, and therefore memorising disconnected facts for the respondent the multiple-choice exams. The author's argument is which will we tend to implement any true try during this continuous study cycle while not a resultant amendment within the method academics square measure instructed. EL may be a national reform model for all faculties that teaches the academics in several ways in which continued employment can amendment heaps in them and after they are going to be back to high school and teach kids they produce learning environments embodying inquiry and genuineness so our youth square measure authorised to affect social group amendment. Baker (2012) ${ }^{[4]}$ investigated an EL model that semiconductor diode students to find out by doing. He mentioned that the educational expedition model takes the students into the sensible world, wherein kids use their creativeness and curiosity as motivation for learning. Several types of research and studies reveal that students in expedition learning faculties attain higher scores than their peers in ancient faculties in subjects like standardized English, reading and mathematics tests, etc. This model is often effective for closing action gaps for ethnic groups and impoverished student populations. The expedition Learning organization partnered with the school's workers, coaching academics to let students become active participants in their educations and to adopt a cooperative mentality that academics share. Students have taken possession and pride within the faculty, cleansing the building and organizing lecture rooms. Klein \& Riordan (2011) ${ }^{[17]}$ investigated experiential skilled development in ELS. victimisation this study teacher square measure instructed to impart qualitative ways of education through innovative ways in which. it's investigated EL structures experiential skilled development for its academics, the strengths and challenges of those experiences, and the way these experiences facilitate academics to implement skills development in their lecture rooms. This analysis focuses on the challenges of academics however they learn and teach the children these unconventional models of teaching and learning. Transmission-based skilled development now and then might not be sufficient for an amendment therefore few academics attend EL lecture rooms. This helps and supports EL faculty style to life. For the survival of the organization, although the academics don't seem to be instructed in an exceedingly special method, there ought to be some way out on however the academics will instill important and deep learning expeditions for school students. Beesley et al. (2010) ${ }^{[6]}$ investigated EL Schools within the context of a theory of action and literature review of motivation, character, and engagement. They ended that the constructs highlighted during this theory of action are supposed to capture the goals of the far side learning activities for school students. In an EL, students are expected to exhibit prosocial behavior that promotes the expansion of a healthy learning atmosphere for everybody. Learning expeditions need the youngsters to be concerned or participate intensely so that they become extremely impelled and develop masteryoriented characteristics that support their self-efficacy. Doing all this creates an environment that encourages; (i) engagement through effort (ii) persistence (iii) civic engagement and (iv) identification with faculty. per the reviewed literature associated with ELS theory, the learner is given complete attention. The learners do not solely develop during a precise domain however development is within the social/emotional/motivational domains, therefore, development in tutorial domains is oblivious and connected. Different types of feedback loops facilitate ELS in the development of multiple aspects of the learner which can expectedly have a robust and long-lasting impact on more life academically and much. Riordan, Klein \& Emily. (2010) [35] Authors investigated Expeditionary Learning Schools Support Classroom Teachers in Tackling Issues of Sustainability. Environmental education (EE) pedagogy is grounded in an exceedingly read of teaching as a "creative and dynamic method within which pupils and educators have engaged along in an exceedingly hunt for solutions to environmental issues." but it's not solely the scholars WHO would like support participating during this search however the teachers--in making dynamic, rigorous exploration of environmental problems. It promotes skilled development to support teachers' pedagogic approaches to EE, which take issue from ancient teaching approaches. These embrace knowledge domain designing, active investigation of native problems, and sturdy participation--with students--in activities around environmental improvement. This analysis explores environmentally property faculty practices through a case study of however one faculty, EL, provides teacher skilled development. This skilled development promotes environmental-based education that aims to support 
lecturers in learning and teaching concerning ecosystems and also nature and has as its goal a bearing on student expertise and work. Embedded among this study, and also the focus of this text, are two case studies of teachers in urban schools developing and implementing science expeditions, a primary pedagogic observation within the EL. The goal of each expedition was to interact with students in exploring ideas of property among their communities, families, and also the larger world. Klein \& Riordan (2009) ${ }^{[18]}$ investigated Teachers in Expeditionary Learning Schools Implement Professional Development. The current schools' movement has accrued the number of organizations seeking to vary education with styles that need educators to rethink their understandings of info, teaching, and learning. The key to the success of those schools is however well the lecturers will learn and implement the look, egg-laying an important burden on the schools, or, the mediator organization, to supply adequate skilled development. Several of those organizations have endowed heavily in skills development as a way of guaranteeing that the teaching in their schools is in step with the vision of the organization. This text presents findings regarding however lecturers in one such instructional organization, EL schools, remodeled skilled development experiences into learning experiences for his or her students. whereas policy manufacturers and educators intelligibly involved regarding the link between skilled development and student learning, the authors wanted to look at the intricacies of skilled development implementation not just "for" whether or not or not they saw a mirrored image of skilled development in teachers' follow however additional significantly, "how" they saw it enforced by lecturers and therefore the context and quality of that implementation. The authors believe that this link between skilled development and student learning is vital for organizations that specialize in developing the abilities and information of room lecturers. Martin et al. (2009) ${ }^{[24]}$ tried to assess the development of environmental virtue in grade VII-VIII learners in an EL school using an instrument developed for this study, the Children's Environmental Virtue Scale (CEVS). This study was obtained by administering the CEVS survey to students in an EL school that enclosed a 10-week EL. Results indicated a decrease within the mean environmental virtue scores for school students who participated in the EL. Fischer et al. $(2007)^{[10]}$ investigated the roles of expedition learning will play intolerance and democratic education. They found differing kinds of tools helped them to create a record of expertise whereas increasing different aspects of expedition learning by planning the training atmosphere, building activities, planning lessons, and organising the atmosphere for learning. With the assistance of technology, students will produce maps and documents associated with social problems and historical places they encounter throughout their cultural exchange with the assistance of digital video, photography, and web site style. Taylor (1999) [41] investigated an integrated learning system (ILS) and its impact on examination performance in arithmetic. This study estimates the impact of victimisation learning expeditions. An integrated learning system primarily based upon computer-assisted learning. This study is predicated upon expertise in one faculty throughout the primary year of its introduction into the school information. Multivariate analysis ways were utilized to estimate the applied math relationship between the examination scores achieved by pupils at the top of the school year and therefore the time spent victimisation learning expedition, taking into consideration the influence of the initial level of attainment of every pupil as indicated by their scores. Although the initial level of accomplishment is that the predominant informative variable of the level achieved within the end-ofyear arithmetic examinations, time spent victimisation the educational Expedition software package was conjointly found to enhance performance considerably. The conclusion was that ILS will cause favourable outcomes by maximising the supply of this resource throughout the school day.

\section{An Overview of Reviewed Literature}

The literature review shows several studies on a variety of le arning styles-interactive, social, innovative, experiential, game-based, self-regulated, integrated, and expeditionary le arning. After the scrutiny of relevant literature, a need was felt for the development of relevant tools to study the impact of learning styles to discover the facilities provided by the school and determine the strategy adopted to fulfill the purpose.

\section{References}

1. Al-Abdullatif AM, Wang S (Ed.). Investigating Self-Re gulated Learning and Academic Achievement in an E-L earning Environment: The Case of K 12 Flipped Classr oom 2020.

https://doi.org/10.1080/2331186X.2020.1835145

2. Aljohani SR, Daud A, Abbasi RA, Alowibdi JS, Basheri M, Aslam MA. An Integrated Framework for Course Adapted Student Learning Analytics Dashboard. Computers in Human Behavior 2019;92:679-690, 0747-5632.

3. Asfeldt M, Hvenegaard G, Rebecca PS. Group Writing, Reflection, and Discovery: A Model for Enhancing Learning On Wilderness Educational Expeditions. Journal of Experiential Education 2018;41(3):241-260. https://doi.org/10.1177/1053825917736330

4. Baker CR. (Sep 22, 2012, 12:42 am MDT). The Expeditionary Learning Model Lets Students Learn by Doing. http://www.deseretnews.com/article/865562955/ Expeditionary-learning-model-lets-students-learn-bydoing.html?pg=all

5. Barrer IN, Haimson J. Impacts of Five Expeditionary Learning Middle Schools on Academic Achievement 2013.

6. Beesley A, Clark T, Barker J, Germeroth C. Expeditionary Learning Schools: Theory of Action and Literature Review of Motivation, Character, and Engag ement 2010. http://files.eric.ed.gov/fulltext/ED517451.pdf

7. Camillo LD. A Teacher's Perceptions of Teaching with Expeditions in A Tested History Course. Social Studies Research \& Practice 2015;10(2):44-55, 12.

8. Cazan AM. An Intervention Study for the Development of Self-Regulated Learning Skills 2020. https://doi.org/10.1007/s12144-020-01136-x

9. Cheng KH, Tsai CC. A Case Study of Immersive Virtual Field Trips in an Elementary Classroom: Students' Learning Experience and Teacher-Student Interaction Behaviors. Computers \& Education 2019;140:103600, 0360-1315.

10. Fischer JM, Mazurkiewicz G, Kellough Z, Preslan J. Building Connections and Community: The Roles 
Expeditionary Learning Can Play in Tolerance and Democratic Education 2007.

https://www.questia.com/library/journal/1G1-

163153354/building-connections-and-community-theroles-expeditionary

11. Fleming J, Pretti TJ. The Impact of Work-Integrated Learning Students on Workplace Dynamics. Journal of Hospitality, Leisure, Sport \& Tourism Education 2019;25:100209, 1473-8376.

12. Ikpeze C. Increasing Urban Students' Engagement with School: Toward The Expeditionary Learning Model. Journal of Urban Learning, Teaching, and Research 2013;9:55-64.

13. Jahnke I, Norqvist L, Olsson A. Digital Didactical Designs Of Learning Expeditions, ECTEL 2014, https://doi.org/10.1007/978-3-319-11200-8_13

14. Jih HJ, Reeves TC. Mental models: A research focus for interactive learning systems. ETR\&D 1992;40:3953. https://doi.org/10.1007/BF02296841

15. Khenissi MA, Essalmi F, Jemni M, Kinshuk, Graf S, Chen NS. Relationship between Learning Styles and Genres of Games. Computers \& Education 2016;101:114, 0360-1315.

16. Kimmes L. The Benefits of Experiential Learning in an Outdoor Expedition Setting. School of Education Student Capstone Projects 2017, 92. https://digitalcommons.hamline.edu/hse_cp/92

17. Klein EJ, Riordan M. Wearing the Student Hat: Experiential Professional Development in Expeditionary Learning Schools. Journal of Experiential Education 2011;34(1):35-54.

18. Klein EJ, Riordan M. Putting Professional Development into Practice: A Framework for How Teachers in Expeditionary Learning Schools Implement Professional Development. Teacher Education Quarterly 2009;36(4):61-80.

19. Kucuk S, Sisman B. Behavioral Patterns of Elementary Students and Teachers in One to One Robotics Instructi on. Computers \& Education 2017;111:31-43, 03601315.

20. Labib E, Canos J, Penades MC. On The Way to Learning Style Models Integration: A Learner's Characteristics Ontology, Computers in Human Behavior 2017;73:433-445, 0747-5632.

21. Mackenzie SH, Son JS, Eitel K. Using Outdoor Adventure to Enhance Intrinsic Motivation and Engagement in Science and Physical Activity: An Exploratory Study. Journal of Outdoor Recreation and Tourism 2018;21:76-86, 2213-0780.

22. Macpherson C, Haggans CJ, Reicks M. Interactive Homework Lessons for Elementary Students and Parents: A Pilot Study of Nutrition Expedition. Journal of Nutrition Education 2000;1:49-55, 0022-3182.

23. Madani K, Pierce TW, Mirchi A. Serious Games on Environmental Management. Sustainable Cities and Society 2017;29:1-11, 2210-6707.

24. Martin B, Bright A, Cafaro P, Mittelstaedt R, Bruyere B. Assessing the Development of Environmental Virtue in 7th and 8th Grade Students in an Expeditionary Learning Outward Bound School. Journal of Experiential Education 2009;31(3):341-358. https://doi.org/10.1177/105382590803100303

25. Mawdsley A, Willis S. Exploring an Integrated Curriculum in Pharmacy: Students Perspectives on the
Experienced Curriculum and Pedagogies Supporting Integrative Learning. Currents in Pharmacy Teaching and Learning 2019;1(5):450-460, 1877-1297. https://doi.org/10.1016/j.cptl.2019.02.006

26. McCurdy HE. Learning from History: Low-Cost Project Innovation in the U.S. National Aeronautics and Space Administration. International Journal of Proj ect Management 2013;31(5):705-711, 0263-7863.

27. Mirhosseini F, Lavasani M, Hejazi E. The Effectiveness of Self-Regulation Learning Skills on Motivational and Academic Variables among Students. World Family Medicine Journal 2018;16:68-75. 10.5742/MEWFM.2018.93385.

28. Moos DC, Ringdal A. Self-Regulated Learning in The Classroom: A Literature Review on the Teacher's Role. Education Research International 2012;15:423284. https://doi.org/10.1155/2012/423284

29. Owens SA. We Teach How We've Been Taught: Expeditionary Learning Unshackling Sustainability Education in U.S. Public Schools. Journal of Sustainability Education 2013;5:2151-7452.

30. Ozan C, Gundogdu K, Bay E, Celkan HY. A Study on University Students' Self-Regulated Learning Strategies Skills and Self-Efficacy Perceptions in Terms of Different Variables. Social and Behavioral Sciences 2012;46:1806-1811, 1877-0428, https://doi.org/10.1016/j.sbspro.2012.05.383.

31. Park J, Kim S, Kim A, Yi MY. Learning to Be Better at the Game: Performance Vs. Completion Contingent Reward for Game-Based Learning. Computers \& Education 2019;139:1-15, 0360-1315.

32. Pintrich PR. Understanding Self-Regulated Learning 1995. https://doi.org/10.1002/tl.37219956304

33. Raptis GE, Fidas C, Avouris N. Effects of MixedReality on Players Behaviour and Immersion in A Cultural Tourism Game: A Cognitive Processing Perspe ctive. International Journal of Human-Computer Studies 2018;114:69-79, 1071-5819.

34. Reid P, Kampman H. Exploring the Psychology of Extended-Period Expeditionary Adventurers: Going Knowingly into the Unknown. Psychology of Sport and Exercise 2020;46:101608, 1469-0292. https://doi.org/10.1016/j.psychsport.2019.101608.

35. Riordan M, Klein EJ. Environmental Education in Action: How Expeditionary Learning Schools Support Classroom Teachers in Tackling Issues of Sustainability. Teacher Education Quarterly 2010;37(4):119-137.

36. Robledo LAC, Ayala AP. A Holistic Self-Regulated Learning Model: A Proposal and Application in Ubiquitous Learning. Expert Systems with Application 2019;123:299-314, 0957-4174.

37. Roick J, Ringeisen T. Students Math Performance in Higher Education: Examining the Role of SelfRegulated Learning and Self-Efficacy. Learning and Individual Differences 2018;65:148-158, 1041-6080.

38. Schaffhauser D. Denver Will Expand Its Use of Expedit ionary Learning's Open Source Curriculum 2015. https://thejournal.com/articles/2015/06/03/denver-willexpand-its-use-of-expeditionary-learning-open-sourcecurriculum.aspx

39. Stern PR. Principled Neglect and Compliance: Responses to NCLB and the CCSS at an Expeditionary 
Learning Middle School. Leadership and Policy in Schools 2016;15(4):448-480 https://doi.org/10.1080/15700763.2015.1047034

40. Tan TAG, Vicente AJ. An Innovative Experiential and Collaborative Learning Approach to an Undergraduate Marketing Management Course: A Case of the Philippines. The International Journal of Management Education 2019;17(3):100309, 1472-8117.

41. Taylor L. An Integrated Learning System and Its Effect on Examination Performance in Mathematics. Computers \& Education 1999;32(2):95-107, 03601315. https://doi.org/10.1016/S0360-1315(98)00054-2

42. Torrano F, Gonzalez-Torres MC. Self-Regulated Learning: Current and Future Directions. Electronic Journal of Research in Educational Psychology 2004.

43. Vale GL, Carr K, Dean LG, Kendal RL. The Cultural Capacity of Human and Nonhuman Primates: Social Learning, Innovation, and Cumulative Culture. Evolution of nervous systems (2nd ed.). Oxford: Academic Press 2017, 475-508.

44. Wong E, Nguyen TV. Introduction of an Integrated Curriculum: Early Outcomes and Experiences within a Large Private University. Currents in Pharmac y Teaching and Learning 2019;11(5):528-532, 1877 1297.

45. Yot-Domínguez C, Marcelo C. University Students Self-Regulated Learning Using Digital Technologies 2017;14:38. https://doi.org/10.1186/s41239-017-0076-8

46. Zoltowski APC, Teixeira MAP. Development of SelfRegulated Learning in College Students: A Qualitative Study 2020;25:1413-7372, 1807-0329.

https://doi.org/10.4025/psicolestud.v25i0.47501 